Revue

Revue de l'histoire des religions

de Ihistoire des religions

$2 \mid 2017$

Les juifs et la nation au Moyen Âge

\title{
Les Juifs dans les écrits castillans : peuple, genre ou nation?
}

The Jews in Castilian Medieval literature: people, genus or nation?

\section{Adeline Rucquoi}

\section{OpenEdition}

\section{Journals}

Édition électronique

URL : http://journals.openedition.org/rhr/8748

DOI : $10.4000 /$ rhr.8748

ISSN : 2105-2573

\section{Éditeur}

Armand Colin

\section{Édition imprimée}

Date de publication : 1 juin 2017

Pagination : 359-384

ISBN : 978-2-200-93126-1

ISSN : 0035-1423

Référence électronique

Adeline Rucquoi, «Les Juifs dans les écrits castillans : peuple, genre ou nation? », Revue de l'histoire des religions [En ligne], 2 | 2017, mis en ligne le 01 juin 2019, consulté le 07 janvier 2021. URL : http:// journals.openedition.org/rhr/8748; DOI : https://doi.org/10.4000/rhr.8748 


\section{Les Juifs dans les écrits castillans : peuple, genre ou nation?}

Si les Juifs castillans eurent très tôt conscience d'être une communauté à part, faisaient-ils partie intégrante du royaume ou étaient-ils des étrangers aux yeux des Chrétiens? Le concept de «nation » est tardif en Castille et il convient d'examiner la question en précisant la signification des vocables, latins et castillans, de Iudaei et judíos, d'Hebreus, de Iudeorum populus, populus Israelitici, genus ou generatio Iudaeorum, de gentes et de pueblo, dans les discours juridique, historique et religieux produits en Castille dans les derniers siècles du Moyen Âge, afin de comprendre le glissement sémantique qui s'opéra entre le XIII et le XV siècle, confondant la question $d u$ sang avec celle du lignage, et excluant Juifs et conversos de la nation castillane en construction.

\section{The Jews in Castilian Medieval literature: people, genus or nation?}

Castilian Jews came to see themselves as a separate community very early on, but did the Christians see them as part of the kingdom or rather as foreigners? This paper aims at understanding the semantic shift that took place in the kingdom of Castile between the $13^{\text {th }}$ and the $15^{\text {th }}$ century, and which led Christian theologians and jurists to exclude Jews and conversos from Castilian nation-building. The concept of "nation" appeared late in Castile and, to analyze the issue, it is advisable to define the meaning of the Latin and Castilian words Iudaei and judíos, Hebreus, Iudeorum populus, populus Israelitici, genus or generatio Iudaeorum, gentes and pueblo, which were used in legal, historical and religious texts written in the kingdom of Castile during the Late Middle Ages. 
«Sache votre roi que le nom de notre pays, au centre duquel nous vivons, est Sefarad dans la langue sainte, tandis que dans la langue des Arabes qui résident dans le pays c'est al-Andalus. Le nom de la capitale du royaume est Cordoue. Sa longueur est de 25000 coudées et sa largeur de 10000. Elle est située à gauche de la mer qui baigne notre pays et qui provient de la grande mer qui entoure toute la terre... $»^{1}$.

Ainsi s'adressait au roi des Khazars Hasdaï ibn Shaprut, chef de la communauté juive de Cordoue au milieu du $\mathrm{x}^{\mathrm{e}}$ siècle. Les Juifs d'Espagne manifestèrent très tôt la conscience qu'ils avaient d'être une communauté, dotée d'une loi particulière, d'une langue « sainte » et d'une histoire. En même temps, ils paraissent s'être sentis profondément attachés à l'Espagne où ils vivaient, dont ils parlaient les langues, devaient respecter les lois et à l'histoire de laquelle ils rattachaient la leur².

Qu'en était-il du côté des chrétiens, et notamment des Castillans ? Que représentaient pour eux les Juifs ? Étaient-ils une partie des habitants du royaume comme d'autres ou un peuple étranger? Quels sont les termes employés pour les qualifier ou les définir?

L'Espagne chrétienne s'est forgée dans la droite ligne des concepts de l'empire romain chrétien, que les Wisigoths avaient appris durant des siècles de voisinage et d'échanges avec les Romains d'Orient. Le roi y est donc le « vicaire de Dieu » dans son royaume et il devra Lui rendre des comptes aussi bien dans le domaine matériel que dans le domaine spirituel. Les textes de lois $\mathrm{du} \mathrm{XIII}^{\mathrm{e}}$ siècle le rappelleront, sanctionnant ainsi la victoire des monarques péninsulaires sur l'évêque de Rome quant aux investitures des évêques. Le «patronage royal », comme il sera appelé à l'époque moderne, durera jusqu'à la fin du $\mathrm{XX}^{\mathrm{e}}$ siècle $^{3}$.

1. Carlos del Valle Rodríguez, La escuela hebrea de Córdoba. Los orígenes de la escuela filológica hebrea de Córdoba, Madrid, Editora Nacional, 1981, p. 319-346.

2. Adeline Rucquoi, "Le nom de notre pays est Sefarad dans la langue sainte... Être juif dans l'Espagne médiévale: altérité ou identité ? ", $13^{\mathrm{e}}$ Conférence Alberto Benveniste, Centre Alberto-Benveniste d'études sépharades et d'histoire socioculturelle des Juifs, Paris, 2014, p. 15-45.

3. Adeline Rucquoi, "Cuius rex, eius religio : Ley y religión en la España medieval », Las representaciones del poder en las sociedades hispánicas, ed. Óscar Mazín, México, El Colegio de México, 2012, p. 133-174. 
Par ailleurs, le concept de «nation» est tardif en Castille. Il apparaît notamment lors du concile de Bâle en 1434 lorsque l'évêque de Burgos Alfonso de Cartagena parle de sa patrie comme de «nation d'Espagne » et revendique pour elle les bancs les plus honorifiques. Au Moyen Âge, l'Espagne est avant tout une «terre»-tierra. Celui qui vit dans le pays appartient en premier lieu à cette «terre ». Il n'est jamais un «sujet» du roi. Il est un natural de la terre d'Espagne. Le monarque est, lui, le «seigneur naturel» de cette même «terre» qui joue donc un rôle intermédiaire fondamental : la première fidélité est celle que l'on doit à la terre, et cette fidélité s'inscrit dans le domaine du droit naturel, donc du droit divin. Et si le mot «patrie » apparaît quelquefois, celui de «nation » est pratiquement absent ${ }^{4}$.

Comment furent donc perçus les Juifs dans ce cadre ? Il n'est peut-être pas inutile ici de préciser la signification médiévale des vocables utilisés par les auteurs castillans et, pour ce faire, les Étymologies d'Isidore de Séville, si largement représentées dans les bibliothèques médiévales depuis le $\mathrm{VII}^{\mathrm{e}}$ siècle, apporteront les définitions qui nous permettront de ne pas tomber dans l'anachronisme.

Les Juifs, lorsqu'ils sont mentionnés dans l'ouvrage, le sont généralement comme Iudaei ou comme Iudaeorum populus, le «peuple des Juifs » (Etym. VIII, 1). Puis, après avoir expliqué le mot «hérésie », le métropolitain d'Hispalis signale dans le même chapitre que secta vient de «suivre » et de « soutenir » et définit le mot comme étant un habitus animorum, une disposition de l'âme, une idéologie qui en matière de religion est éloignée des autres (Etym. VIII, 3, 4).

Dans un autre livre, il déclare que populus s'applique à «une multitude humaine, unie par un droit consensuel et une concorde collective » et ajoute que, sous ce terme de populus, sont compris tous les citoyens, alors que sous celui de plebs seule est mentionnée la plèbe, sans l'élite (Étym. IX, 4, 5). « Nation » n'a pas droit à une définition spécifique dans les Étymologies et le mot apparaît lié à celui de gens. La gens, dit Isidore, « est la multitude de ceux qui

4. Adeline Rucquoi, "Tierra y gobierno en la Península ibérica medieval », Las Indias occidentales, procesos de incorporación territorial a las Monarquías ibéricas, eds. Óscar Mazín \& José Javier Ruiz Ibáñez, México, El Colegio de México, Red Columnaria, 2012, p. 43-67. 
proviennent d'une même origine ou d'une autre nation distincte selon son identité - collectio - propre, comme la Grèce, l'Asie » et il souligne que "nation dérive de naître » (Étym. IX, 2, 1); plus loin, il indique que les nations tirent leur origine d'ancêtres bien définis et qu'en raison de cette parenté on les appelait gentes (Étym. IX, 4, 4).

En simplifiant, on pourrait dire que le terme gens, apparemment équivalent à celui de natio, définit chez Isidore un groupe humain en fonction d'une origine ou d'un fondateur spécifiques, donc de son histoire ou généalogie, tandis que celui de populus s'attache à une communauté vivant sous une même loi et en bonne entente, et que celui de secte définit l'appartenance à une idéologie. L'appellation «les Hébreux» ou «les Juifs» renvoie donc à l'origine, Héber, arrière-petit-fils de Sem, pour les premiers, Juda pour les seconds, et Israël, fils d'Isaac pour les dix tribus qui ne descendaient pas de Juda. Et l'expression populus Iudaeorum définirait la communauté politique à un moment donné.

Quelques siècles plus tard, et bien qu'ils connussent les œuvres du métropolitain d'Hispalis, les auteurs du glossaire copié à San Millán de la Cogolla au milieu du $\mathrm{x}^{\mathrm{e}}$ siècle ne proposèrent, parmi les 20000 mots, aucune entrée pour natio ou populus. À gens, néanmoins, ils donnèrent comme définition natio, et à gentes celle de nationes, genus étant défini comme « origine». Populare, en revanche, ainsi que ses dérivés, signifiait à l'époque " dévaster ", « spolier» et secta y est définie à la fois comme ce que l'on suit et comme l'équivalent d' « hérésie $»^{5}$.

Ces quelques considérations préalables faites, les Juifs apparaissent dans de très nombreux textes, et nous avons choisi ici de nous pencher sur le discours juridique, le discours historique et le discours religieux en y cherchant les définitions du Juif ou des Juifs.

5. Claudio García Turza \& Javier García Turza, Fuentes españolas altomedievales. El códice emilianense 46 de la Real Academia de la Historia, primer diccionario enciclopédico de la Península ibérica, Madrid, Real Academia de la Historia, 1997, p. 360, 466 et 515. 


\section{LE DISCOURS JURIDIQUE}

Jusqu'au milieu du XIII ${ }^{\mathrm{e}}$ siècle, les chrétiens de la Péninsule avaient pour loi celle qui était écrite dans le Liber Iudicum ou Lex wisigothorum. Élaboré au milieu du $\mathrm{VII}^{\mathrm{e}}$ siècle, celui-ci consacrait un livre entier, le $\mathrm{XII}^{\mathrm{e}}$, à «tous les hérétiques et aux Juifs». Le roi y rappelle dès l'abord que le Dieu vivant a « revêtu de l'immortalité d'une seule tunique la diversité à la fois des nations et des hommes » et qu'il lui incombe de gouverner par la loi et d'extirper les hérésies de son royaume. Tout en insistant sur la « perfide fourberie de l'erreur judaïque »-perfida iudaici erroris calliditas - et sur leur malice - nequitia-, le texte se contente d'opposer, dans ses canons, "les Juifs» aux «chrétiens ». En de rares occasions, il parle de «leur secte» ou de la «secte judaïque », en une autre de la «gens iudaica», et dans la formule de serment exigée des Juifs qui se convertiraient sont évoqués « le peuple israélite et les autres gentes ». Deux lois, attribuées au roi Ervige, mentionnent enfin le conventus des Juifs qui se réunissait pour célébrer ses fêtes ${ }^{6}$. Le but du Liber Iudicum est clairement d'éviter que les Juifs ne convertissent des chrétiens et de limiter pour cela leurs droits.

Le Liber Iudicum resta en vigueur pendant des siècles. En 1118, encore, lorsque le roi Alphonse VII accorda un nouveau Fuero aux mozarabes, aux Castillans et aux Francs de Tolède, il rappela qu'aucun Juif ou converti ne devait avoir de pouvoir sur des chrétiens, et que tout accusé d'avoir tué « un Chrétien, un Juif ou un Maure » devait être jugé per librum iudicum ${ }^{7}$.

Les Étymologies furent traduites en langue vulgaire, peut-être dans la seconde moitié du XIII ${ }^{\mathrm{e}}$ siècle, et fournirent aux écrivains et rédacteurs les définitions isidoriennes qui continuaient à être utiles. "Gens, qui veut dire les gens, est la multitude née d'un même principe ou d'une autre nation répartie selon sa proximité ou son union, comme la Grèce ou l'Asie », et "Populus, ou peuple, est le rassemblement d'une multitude d'hommes qui s'accompagne de l'octroi d'un droit et d'un accord commun »,

6. Fuero Juzgo en latín y castellano, Madrid, Real Academia Española, 1815, lib. XII, p. 139-162.

7. Tomás Muñoz y Romero, Colección de fueros municipales y cartas pueblas, Madrid, Atlas, 1978, p. 365-366. 
définition qui se complète par l'explication du fait que populus signifie l'ensemble des citoyens, c'est-à-dire «toute la ville », alors que plebs ne s'applique qu'au menu peuple ${ }^{8}$. Fidèle à ses sources, le roi Alphonse $X$ de Castille (1252-1284) précisa également, dans la seconde Partida ce que voulait dire «peuple»-pueblo : «Certains considèrent que les petites gens, comme les artisans et les paysans, sont le peuple. Mais ce n'est pas ainsi (...). Peuple signifie l'ensemble de tous les hommes en commun, des grands, des moyens et des petits. Car ils sont tous nécessaires et aucun ne peut manquer, parce qu'ils doivent s'entraider les uns les autres afin de vivre bien et d'être protégés et gardés »'.

Les textes légaux du XIII ${ }^{\mathrm{e}}$ siècle recourent souvent au seul nom de «Juifs », comme par exemple dans le titre II du livre IV du Fuero Real qui interdit les pratiques usuraires et précise que ces prescriptions s'adressent « aussi bien aux chrétiens qu'aux Juifs ou aux maures, et à tous ceux qui prêteraient à usure $»^{10}$. Mais dans la septième Partida, Alphonse $\mathrm{X}$ donne la définition du mot : «les Juifs sont une sorte de gens qui ne croient pas en la foi de Notre Seigneur Jésus Christ, mais les grands seigneurs des chrétiens ont toujours toléré qu'ils vivent parmi eux », et il ajoute que «on appelle Juif celui qui croit et observe la loi de Moïse à la lettre, et qui se fait circoncire, et qui fait les autres choses que mande sa loi »; plus bas, le législateur indique que «anciennement, les Juifs furent grandement honorés et eurent de grands privilèges par rapport à toutes les autres gentes; car ils étaient les seuls à être appelés peuple de Dieu $»^{11}$. La crucifixion et le refus de reconnaître le Messie ont ainsi dépouillé les Juifs de leur royaume et de leurs

8. Joaquín González Cuenca, Las Etimologías de San Isidoro romanceadas, Salamanca - León, Universidad de Salamanca, 1983, t. I, p. 306 et 334.

9. Alfonso X el Sabio, Las Siete Partidas, Salamanca, 1555, II, x, 1: «Cuydan algunos quel pueblo es llamado la gente menuda, assi como menestrales e labradores. E esto non es ansi (...) Pueblo llaman el ayuntamiento de todos los omes comunalmente, de los mayores e de los medianos e de los menores. Ca todos son menester e non se pueden escusar, por que se han de ayudar unos a otros, por que puedan bien bivir e ser guardados e mantenidos ».

10. Alfonso X el Sabio, Fuero Real, IV, II, 6, ed. Real Academia de la Historia, Madrid, 1836, p. 119: « ... et esto sea tan bien en cristianos como en judios, como en moros, como en todos aquellos que dieren a usuras ».

11. Alfonso X el Sabio, Las Siete Partidas, VII, Xxiv, prol., 1 et 3: «Iudios son una manera de gente que como quier que non creen la fe de nuestro señor Iesu Christo, pero los grandes señores de los Christianos sienpre sufrieron que biviessen entre ellos », « Antiguamente los judios fueron muy honrrados e ovieron 
rois, et la diaspora leur a même ôté le nom de «peuple » si l'on en croit les textes du XIII ${ }^{\mathrm{e}}$ siècle.

Les Ordonnances des Cortes interdisent la cohabitation entre chrétiens, Juifs et musulmans, mais les peines encourues s'appliquent de la même façon à tous, comme le prescrit l'article 30 des Cortes de Jérez de 1268, ou interdisent aux Juifs et aux musulmans le prêt à usure au-delà de $25 \%$ annuel et remplacent l'alcalde juif par un chrétien pour les procès entre Juifs comme à Valladolid en 1293. Les procureurs des villes de Castille aux Cortes « révolutionnaires » de 1315 à Burgos demandèrent que les impôts ne fussent pas affermés et que les percepteurs ne fussent «ni des clercs, ni des Juifs ni d'autres hommes révoltés », que les Juifs et les musulmans ne portent pas de noms chrétiens, que les chrétiennes ne vivent pas avec les uns ou les autres et s'attachèrent à réglementer le prêt sur gages et à intérêt ; à la suite des plaintes des procureurs, les monarques durent renouveler les interdictions de cohabitation entre tenants des diverses religions ou celle d'adopter un nom ou des vêtements chrétiens, comme à Valladolid en $1351^{12}$.

Les plaintes relatives aux dettes des chrétiens envers les Juifs et les demandes d'annulation de ces dettes se répètent de Cortes en Cortes, ce qui prouve sans doute l'inefficacité des mesures prises, et l'absolue nécessité du prêt d'argent dans l'économie. Mais cette réitération a poussé de nombreux historiens à accorder aux Juifs un rôle primordial dans le prêt à intérêt. L'étude des testaments passés en Castille montre que de nombreux chrétiens, et surtout chrétiennes, prêtaient également à leurs coreligionnaires en échange de gages et qu'ils étaient souvent plus nombreux que les créanciers juifs. Les Juifs se plaignirent par ailleurs des multiples artifices auxquels recouraient les chrétiens pour ne pas payer leurs dettes. En 1325, ils firent voir au roi Alphonse XI que « beaucoup dans mon royaume, clercs comme laïcs, ont obtenu des bulles du pape et des lettres des prélats qui les excommunient en raison des

muy grand preuillejo sobre todas las otras gentes. Ca ellos tan solamente eran llamados pueblo de Dios».

12. Cortes de los antiguos reinos de León y de Castilla, Madrid, Real Academia de la Historia, t. I, 1861, p. 77, 114-115, 275, 280-285. Cortes de los antiguos reinos de León y de Castilla, Madrid, Real Academia de la Historia, t. II, 1863, p. 18-19. 
dettes qu'ils ont »; le roi ordonna à ses officiers de s'emparer de toutes ces lettres et de les lui remettre, et demanda aux Juifs qui avaient quitté le domaine royal d'y revenir ${ }^{13}$. Quelques années plus tard, en 1348, les Ordonnances données lors des Cortes d'Alcalá tentèrent d'interdire aux chrétiens et chrétiennes le prêt à usure qui relevait, dit le texte, du péché d'avarice, et aux Juifs et Juives, musulmans et musulmanes le prêt à intérêt. Le roi stipula cependant que :

Parce que notre volonté est que les Juifs restent dans nos domaines, et ainsi l'ordonne la sainte Église parce qu' ils doivent encore se tourner vers notre foi et être sauvés comme le disent les prophéties, et pour qu'ils aient de quoi vivre et ce qu'il faut pour bien vivre et être dans notre royaume, nous voulons qu'ils puissent avoir et acheter des biens pour eux et pour leurs héritiers dans toutes les cités, villes et lieux de notre domaine royal et dans leurs territoires. (...) Et que ce qu'ils achèteraient et auraient, que ce soit en plus des biens qu'ils possèdent aujourd'hui où qu'ils soient, et des maisons de leur demeure et des maisons qu'ils posséderaient dans les quartiers juifs ${ }^{14}$.

En 1351, à Valladolid, aux plaintes des villes relatives à la promiscuité entre chrétiens, Juifs et musulmans, à l'impossibilité de reconnaître les non-chrétiens des autres, et aux dettes envers les Juifs, s'ajouta celle de l'autonomie judiciaire dont jouissaient les communautés juives qui avaient leurs propres alcaldes pour régler leurs affaires internes. Les procureurs demandèrent que tous les jugements fussent rendus par les alcaldes ordinaires des villes. Le roi Pierre ${ }^{\text {er }}$ répondit :

Parce que les Juifs sont des gens - giente - francs et qu'ils ont besoin d'être défendus, et parce que s'ils portaient devant tous les alcaldes leurs procès ils seraient grandement lésés et perdraient leurs biens, parce que les chrétiens pourraient les désavantager dans les convocations et requêtes qu'ils feraient, je veux que les Juifs puissent prendre l'un des alcaldes ordinaires de la ville où cela se fait, qui entende et juge leurs litiges dans le domaine civil.

Cet alcalde devait jurer sur les Évangiles qu'il ne percevrait rien de ceux qu'il jugerait, et qu'il défendrait de droit de chacune des parties qui viendraient devant lui ${ }^{15}$.

13. Cortes de los antiguos reinos de León y de Castilla, t. I, p. 379 (Cortes de Valladolid de 1325).

14. Cortes de los antiguos reinos de León y de Castilla, t. I, p. 531-534.

15. Cortes de los antiguos reinos de León y de Castilla, t. II, p. 38-40. 
Comme dans toutes les lois et ordonnances du royaume, l'ensemble des prescriptions s'appliquait à tous, chrétiens, Juifs ou musulmans. Mais il est vrai que, dans la société médiévale hispanique, les catégories sociales se caractérisaient par des privilèges ou des restrictions particulières. Nous connaissons bien celles qui furent le propre de la noblesse qui, en raison de son rôle spécifique - en Castille celui d' «administrateurs» de la res publica aux côtés du roi l'emportait nettement sur celui de défenseurs ${ }^{16}-$, jouissait de privilèges honorifiques, fiscaux et judiciaires. Mais le clergé avait aussi des droits et des devoirs particuliers, ce qui lui conférait un statut à part dans la société. Il n'est donc pas étonnant que les non-chrétiens aient également été soumis à des droits et à des devoirs propres, définis par le roi et donc par la loi.

Les mesures prises dans les textes légaux ne « créaient » pas les catégories, mais légiféraient spécifiquement pour chacune d'elles afin de maintenir l'ordre et l'équilibre dans le royaume. C'est probablement pourquoi elles parlent des «Juifs» comme elles désignent «les clercs», «les maures» ou encore les habitants d'une région particulière soumise à un fuero: en 1351, le roi rappela ainsi aux «prélats, hidalgos, autres hommes puissants, cités, villes et lieux de Galice» qu'ils devaient surveiller leurs troupeaux et éviter qu'ils ne détruisent les récoltes «comme le prescrit le fuero de León qui est le leur $»^{17}$. Les nobles en rébellion contre le roi Alphonse X en 1273 avaient de fait exigé qu'il « concède en premier lieu les fueros et les privilèges et les us et coutumes aux ordres, et aux églises, et aux hidalgos, aux chrétiens et aux Juifs et aux maures, ceux qu'ils avaient du temps de son père et de son arrière-grand-père $»^{18}$. Et si le roi prélevait une partie de la dîme ecclésiastique à son profit - les tercias reales -,

16. Adeline Rucquoi, «Être noble en Espagne aux XIV ${ }^{\mathrm{e}}-\mathrm{XVI}^{\mathrm{e}}$ siècles », Nobilitas. Funktion und Repräsentation des Adels in Alteuropa, herausgegeben von Otto Gerhard Oexle \& Werner Paravicini, Göttingen, Vandenhoeck \& Ruprecht, 1997, p. 273-298.

17. Cortes de los antiguos reinos de León y de Castilla, t. II, p. 68-69.

18. Fernán Pérez de Valladolid, Crónica del rey D. Alfonso X, cap. XLI, ed. Paula Rodgers \& Raysa Amador, Biblioteca Saavedra-Fajardo [http://www. saavedrafajardo.org/Archivos/LIBROS/Libro0153.pdf], p. 97: «primera mente que otorgue fueros et preuillejos et vsos et costunbres a ordenes et a yglesias et a fijos dalgo a xpistianos et a judios et a moros lo que oujeron en tienpo de su padre et de su visahuelo ». 
touchait les revenus des sièges épiscopaux vacants et mettait à contribution les autres pour ses campagnes contre les musulmans du sud, il pouvait aussi, en cas de besoin, exiger des Juifs de son royaume des contributions extraordinaires. Il ne les demandait pas au «peuple» des Juifs mais aux aljamas des Juifs, comme le fit Alphonse X en 1280, en utilisant pour les communautés non-chrétiennes établies dans les villes du royaume le mot arabe al-yama' $a$, le groupe, la congrégation, le conventus ${ }^{19}$.

Cette insertion dans ce que nous appellerons la «nation» castillane, si elle ne signifie pas une égalité de droit impensable au Moyen Âge, confère néanmoins à chaque groupe une personnalité au sein d'une communauté soumise à un même roi et aux mêmes lois générales. Les Juifs sont alors un groupe parmi les autres dans le royaume.

\section{LE DISCOURS HISTORIQUE}

Dès le milieu du $\mathrm{XIII}^{\mathrm{e}}$ siècle, la langue vernaculaire devient une langue savante et les chroniques rédigées sous l'égide du roi Alphonse X le Sage (1252-1284) le sont désormais en espagnol. Dans l'immense majorité des cas « les Juifs » - los judíos - ne sont désignés que sous ce nom générique, simple traduction du terme antérieur «Iudaei ». Dans l'Estoria de España, histoire officielle de l'Espagne, « les Juifs », le «peuple des Juifs », ou la «gens des Juifs » figurent indistinctement, même si la première qualification est la plus employée. On trouve ainsi : "Après la mort de Moïse, qui fut le chef du peuple d'Israël selon la Bible, Josué occupa sa place et garda longtemps la gens des Juifs $»^{20}$ ou, plus avant, Hérode Agrippa « vint ensuite en Judée et les Juifs le reçurent avec

19. Fernán Pérez de Valladolid, Crónica del rey D. Alfonso X, cap. LXXv : [Le roi] « vjno a Valladolid et dexó y él vn sello de los suyos con sus ofiçiales et libraron cartas para todo el reino en grand poridad en que enbió mandar que todas las aljamas de los judios fuesen presos en vn dia de sabado. E desque fueron presos todos, pleytearon con ellos el rey don Alfonso por doze mjll marauedis cada dia de aquella moneda que corria $»$.

20. Primera Crónica General de España, ed. Ramón Menéndez Pidal \& Diego Catalán, Madrid, Gredos, 1977, p. 31: "despues de la muerte de Moysen, que fue cabdiello del pueblo de Israel segund cuenta la Biblia, fico Josue en so logar que mantouo grand tiempo la gente de los iudios". 
beaucoup d'honneur $»^{21}$. La General Estoria, histoire universelle élaborée également par l'entourage du roi Sage, consacre à la même époque de très nombreuses pages aux «Juifs » dans la mesure où la Bible y est largement mise à contribution. Ils y sont appelés en majorité « les Juifs » sans plus, mais dans quelques cas apparaissent comme « le peuple des Juifs » ou « la gens des Juifs $»^{22}$.

Dans l'Estoria de España d'Alphonse X le Sage le mot «nation" n'apparaît qu'une seule fois, dans les ajouts à propos des vertus de la reine Beringuela, mère du roi Ferdinand $\mathrm{III}^{23}$. En revanche, les mots «peuple » et «gens »-au singulier comme au pluriel - apparaissent 270 fois pour le premier et 301 fois pour le second, qu'il s'agisse des peuples en général, du «peuple des Romains » ou de celui d'Israël, du peuple d'une ville ou même du «petit peuple».

La locution «les Juifs » signifie donc, comme «les Romains » ou « les chrétiens », un ensemble défini par une origine commune et une histoire. Celle du «peuple des Juifs » offre pour sa part une connotation de communauté juridiquement organisée et il n'est pas étonnant que l'expression n'apparaisse dans la General Estoria qu'avec les premiers rois d'Israël.

La perception des Juifs par les chrétiens se transforme cependant

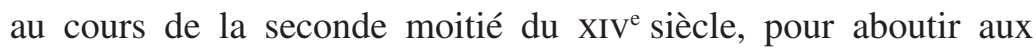
massacres de 1391, à l'enfermement de 1415 et à l'imposition du baptême ou l'expulsion en 1492. Dans sa chronique du roi Pierre ${ }^{\mathrm{er}}$, le noble Pero López de Ayala ne manque pas d'évoquer la légende selon laquelle les musulmans, lors de la conquête de l'Espagne en 711, reçurent l'aide des Juifs qui leur indiquèrent le meilleur

21. Ibid., p. 120: «vinosse luego por Judea et recibieron le los judios muy onradamientre ».

22. General Estoria, t. II, Madrid, Biblioteca National, Ms. 10237, fo 5v: «Et $\mathrm{ap}(\mathrm{re})[\mathrm{er}] \mathrm{cibieron}$ se desto mayor mientre. segunt cuenta la estoria. por aquello que oye $<n>$ dezir del pueblo de los judios. que uenien aquella tierra », t. IV, Vaticana Urb. Lat. 539, fo 211v: « \& uno de los princepes de Alexandre al q<ue $>$ dizien parmenio q<ue $>$ uinie alli pregunto a Alexandre \& dixol. muy grand emperador como fue esto. ca todos los omnes del mundo poro quier $\mathrm{q}<\mathrm{ue}>\mathrm{ymos}$ a oran a ti. $\&$ aoreste tu agora all obispo de la yente de los Judios ».

23. Primera Crónica General de España, p. 735: «Ca esta buena et noble reyna donna Beringella con tamaña acuçia guardo sienpre este fijo y le metio en el coraçon fechos de obras de piedat de omne varon, mançebo et niño, que todo linaie de omnes (...) et toda la naçion, fascas toda gente et toda lengua sintiesse en talente con el fecho en este rey don Fernando ». 
moment pour prendre la ville de Tolède; ennemi du roi Pierre, il n'oublie pas non plus de signaler l'appui apporté au roi par les Juifs de Tolède face à Henri de Trastamare qui s'était emparé de la ville en 1355 et, s'il indique que ce dernier fit souvent massacrer les communautés juives du royaume durant la guerre civile, il explique qu'il s'agissait d'une manœuvre politique : «Et le comte Henri fit faire cette mort des Juifs, parce que les gens - gentes le faisaient de bon gré et, ce faisant, commençaient à craindre et à avoir peur du roi, et prenaient le parti du comte». Sachant que les Juifs étaient sous la protection directe du roi, le futur Henri II de Castille comptait ainsi affaiblir le pouvoir et les ressources économiques de Pierre $\mathrm{I}^{\text {er }}$ et gagner des partisans. Six ans après ces massacres, en 1366, lorsqu'Henri prit la ville de Tolède, il exigea que les Juifs en quinze jours lui versent un million de maravédis afin de payer les Grandes Compagnies ; l'année suivante, les Juifs de Burgos qui s'étaient opposés à son entrée dans la ville finirent par capituler et durent aussi payer un million de maravédis ${ }^{24}$.

Pero López de Ayala, dans son Rimado de Palacio, écrit aussi "Voilà qu'arrivent les Juifs, qui sont prêts / à boire le sang des pauvres malheureux; / ils présentent leurs écrits, qu'ils ont accordés, / et promettent leurs bijoux et leurs dons aux favoris ${ }^{25}$, se faisant l'écho d'un sentiment anti-juif croissant en Castille. Mû par la protection qu'il devait aux Juifs et sollicité par les plaintes à leur sujet, le roi Jean ${ }^{\text {er }}$, en 1380, aux Cortes de Soria, prit des mesures afin de rétablir l'ordre. «Les Juifs de notre royaume», dit-il, ne devront plus lire les prières traditionnelles contre les chrétiens, ni avoir de juges pour les causes criminelles, et il leur est interdit de convertir qui que ce soit à leur religion ${ }^{26}$. Il semble que, devenu roi après l'assassinat de son frère Pierre, Henri II eut comme trésorier un juif de Séville, Yusaf Pichon. La chronique royale raconte que les Juifs virent en lui un traître, le dénoncèrent et le firent emprisonner, avant de le tuer en 1379 au moyen d'un document royal obtenu par ruse; le roi Jean I ${ }^{\text {er }}$ fit exécuter les coupables et interdit dès lors aux Juifs « de faire justice de sang de

24. Pero López de Ayala, Crónicas de los Reyes de Castilla, ed. D. Eugenio de Llaguno Amirola, Madrid, 1779, t. I, p. 31, 61, 184-185, 298-305, 412, 516.

25. Pero López de Ayala, Rimado de Palacio, ed. Jacques Joset, 2 vols., Madrid, Alhambra, 1978, v. 977-980.

26. Cortes de los antiguos reinos de León y de Castilla, t. II, 1863, p. 310-312. 
tout autre Juif », leur ôtant donc la justice criminelle, mesure qui fut ratifiée aux Cortes de $1380^{27}$.

En 1391 eut lieu le premier massacre de communautés juives. Selon Pero López de Ayala, les magistrats sévillans avaient fait fouetter un homme qui maltraitait les Juifs; sur fond de prédications anti-juives de l'archidiacre Ferrán Martínez, « tout le peuple de Séville» se souleva, et ensuite « toutes les villes étaient poussées à détruire les Juifs ». Les Juifs se plaignirent à la ville de Séville et le roi fut alerté et envoya des soldats, mais sans succès. Le chroniqueur, qui ne se fait pas d'illusions, précise que «tout cela fut dû à la convoitise et au désir de voler, semble-t-il, plus qu'à la dévotion», et termine en disant que «cet archidiacre d'Écija fut la cause du soulèvement contre les Juifs de Castille, et à cause de ce soulèvement en ce temps furent perdues les communautés des Juifs de Séville et Cordoue et Burgos et Tolède et Logroño, et beaucoup d'autres dans le royaume (...) et ceux qui échappèrent devinrent très pauvres, et firent de grandes donations aux seigneurs afin d'être protégés de semblables tribulations $»^{28}$.

Dans la mesure où ils étaient une communauté soudée par une loi et un consensus, les Juifs étaient donc un peuple; leur appartenance à une même origine en faisait également une gens ou «nation». Mais depuis leur refus de reconnaitre le Messie, suivi de la perte logique de leur territoire, de leur «patrie», ils ne peuvent plus être une nation. En tant que groupe, ils vivent donc au sein de nations dont la langue et la loi religieuse sont celles d'un sol qui n'est pas le leur. Il leur reste le «lignage », c'est-àdire le fait d'avoir un ancêtre commun dont tous descendent. Dans les années 1480, dans une lettre qu'il adressa à l'une de ses filles qui avait pris le voile, Hernando del Pulgar évoque cependant un prologue de saint Jérôme adressé aux Romains et aux Juifs qui se vantaient de leur «lignage », et où le Père de l'Eglise exaltait les bonnes œuvres plutôt que la naissance ${ }^{29}$.

27. Pero López de Ayala, Crónicas de los Reyes de Castilla, ed. D. Eugenio de Llaguno Amirola, Madrid, 1780, t. II, p. 126-128.

28. Pero López de Ayala, Crónicas de los Reyes de Castilla, t. II, p. 361-362 et 390-391.

29. Hernando del Pulgar, Letras, ed. Rafael Herrera \& Miguel Andúgar, Biblioteca Saavedra Fajardo, p. 76: «Sant Jeronimo, en vn prologo alos romanos y alos judios que se gloriauan de linaje, les reprehende diciéndoles: En tal manera os gloriays de linaje, como si las buenas costumbres no os fiziesen fijos delos 
Les chroniques et les textes légaux mentionnent encore de façon générique «les Juifs» tout au long du $\mathrm{Xv}^{\mathrm{e}}$ siècle. Néanmoins, sous ce terme ancien, le sens a changé. Les juifs du $\mathrm{XV}^{\mathrm{e}}$ siècle, dans la perspective des Castillans qui en parlent, ne sont plus une catégorie d'habitants parmi les autres au sein de la société, juridiquement distinguée par ses privilèges, ses droits et ses devoirs. Ils ne sont plus désormais perçus comme les habitants $\mathrm{du}$ royaume mais comme les fidèles d'une religion. Non plus une religion ancienne, dont on espère la conversion - ceux qui devaient se convertir l'ont fait -, mais une religion radicalement opposée au christianisme.

\section{LE DISCOURS RELIGIEUX}

Tout au long de son histoire, l'Espagne a connu une catégorie particulière d'habitants, celle des Juifs «convertis », depuis les conversions forcées de l'époque wisigothique jusqu'à la dernière en 1492. Or ces conversos, désireux de convaincre à leur tour leurs anciens coreligionnaires, se sont souvent joints aux auteurs chrétiens qui entreprennent, à la suite d'Isidore de Séville, d'obtenir la conversion des Juifs.

La plupart des textes se contentent de parler des « Juifs » ou de s'adresser aux «Juifs », sans aucune spécification particulière. Au début du XII ${ }^{\mathrm{e}}$ siècle, Petrus Alphonsi, converti au christianisme, parle effectivement de ses anciens coreligionnaires comme des Judaei dans le «Dialogue » entretenu par Pierre et Moïse ; dès les premiers échanges, par exemple, Moïse s'adresse à Pierre en lui demandant s'il nie que demeure la loi «que les Juifs suivent actuellement» et qui leur a été donnée par Moïse ${ }^{30}$. À la fin de ce même siècle, depuis León, Martin, chanoine de San Isidoro, rédige une Concordia Novi ac Veteris Testamenti dont la finalité avouée est de raffermir la foi de l'Église catholique, démontrer la perfidie « des Juifs », détruire les superstitions des païens et railler les

sanctos, mejor que el nascimiento carnal » [www.saavedrafajardo.org/Archivos/ LIBROS/Libro0207.pdf].

30. Petrus Alfonsi, Dialogus, dans Migne, Patrologia Latina, t. 157, c. 540: «Nec negas legem, quam in praesenti Judaei tenent, et a Moyse scriptam asseverant, eamdem per omnia, sicut Moyses eam scripsit, permanere ». 
préceptes des philosophes ${ }^{31}$. Dans le $\mathrm{IV}^{\mathrm{e}}$ sermon, intitulé In Natale Domini, Martin de León invective directement ses interlocuteurs : Vos, o Judaei, ou encore : moneo vos, o Judaei, et les accable de reproches; dans ce sermon, les Juifs apparaissent parfois en tant que peuple -o popule stulte et insipiens - ou gens - o perfidi Judaei, o gens prava et perfida ${ }^{32}$.

En revanche, l'archevêque de Tolède Rodrigo Jiménez de Rada qui, à l'instar de Petrus Comestor, rédige au début du XIII ${ }^{\mathrm{e}}$ siècle un Breviarium historie catholice qui commence avec la Création et se termine à la Pentecôte, emploie indifféremment «Juifs » et «Hébreux » mais ne leur accole aucun qualificatif particulier ${ }^{33}$. Il est néanmoins intéressant de voir que le Poema de mío Cid, de la même époque, lorsqu'il évoque la supercherie du Cid remettant à Raquel et Vidas deux coffres scellés emplis de sable en échange de 300 marcs d'argent et 300 marcs d'or (v. 80-2129), ne les qualifie jamais comme «Juifs»; leurs noms et le fait qu'ils doivent garder le secret, afin que ne le connaissent ni les chrétiens ni les musulmans, suffisent bien entendu à les définir comme n'étant ni les uns ni les autres, mais l'épithète ne figure pas dans le poème. Les Juifs font donc partie du «paysage » et, qu'on les apprécie ou non, ils ne sont pas vus comme des étrangers.

Le règne de Pierre $\mathrm{I}^{\text {er }}$ (1350-1367) paraît donc bien être un moment clef dans le changement de perception des Castillans visà-vis des Juifs, même si l'on peut penser que les prescriptions du rabbin Yehuda ben Asher ben Yehiel (mort en 1328), originaire d'Allemagne, à Tolède dans la première moitié du siècle, auquel succédèrent ses fils Jacob (mort en 1343) et Judah (mort en 1349), aient contribué à donner à l'aljama des Juifs de la ville une orientation relativement rigoriste et anti-philosophique. Par ailleurs, l'échec des prophéties messianiques de 1295 avait contribué à désorienter certaines communautés. Dans la première moitié du XIV ${ }^{\mathrm{e}}$ siècle, le rabbin Abner de Burgos se convertit et

31. Martin de Léon, Concordia Novi ac veteris Testamenti, dans Migne, Patrologia Latina, t. 208 et 209.

32. Patrologia Latina, t. 208, c. 106-550. Adeline Rucquoi, «L'invective anti-juive dans l'Espagne chrétienne. Le Sermo IV, In natale Domini II, de Martin de León », Atalaya, 5 (1994) [L'invective au Moyen Âge. France, Espagne, Italie], p. $135-151$.

33. Roderici Ximenii de Rada, Breviarium historie catholice, éd. Juan Fernández Valverde, Turnhout, Brepols (CCCM, 72), 1997. 
prit le nom d'Alfonso de Valladolid, nom sous lequel il rédigea le Moreh Zedek ou Mostrador de Justicia ${ }^{34}$. Quelques décennies plus tard, le médecin du roi se convertissait également, prenait le nom de Juan de Valladolid, écrivait un Tractatus de Concordantia legis Dei et soutenait diverses controverses publiques, notamment à Ávila avec le rabbin Moïse ha-Cohen de Tordesillas; dans son traité, dont nous ne possédons qu'une version latine, figure l'appellation générique Iudaei ${ }^{35}$.

À la suite des massacres de 1391 et des mesures d'enfermement prises en 1412, le nombre des conversos s'accroît notablement. Comme leurs prédécesseurs, certains d'entre eux rédigent des traités polémiques contre leurs anciens coreligionnaires afin de les pousser également à la conversion. Parallèlement, des auteurs chrétiens semblent parfois confondre dans leurs écrits les Juifs et les « judaïsants » et, s'ils prennent la défense des conversos, ils ne prennent bien évidemment pas celle des Juifs, qu'ils les ignorent ou reprennent à leur sujet les anciennes accusations.

L'évêque de Burgos Pablo de Santa María qui, rabbin de la communauté juive de sa ville sous le nom de Salomon ha-Lévi, s'était converti au christianisme en 1390 ou 1391, affirma dans son Scrutinium Scripturarum, rédigé vers 1430-1435, que les Juifs d'Espagne avaient joui pendant très longtemps d'une place prééminente dans le royaume - Iudaei magnos habebant status -, qu'ils avaient exercé de hautes fonctions dans la maison et l'administration du roi, parfois même au-dessus des «fidèles ", au point que les «fidèles » qui leur étaient soumis les révéraient et les craignaient, mettant en péril leur âme. Pour Pablo de Santa María, la situation avait commencé à changer en 1358 avec l'emprisonnement, puis l'exécution, par le roi Pierre Ir $^{\text {r de }}$ «celui qui était le plus grand parmi les Juifs», le trésorier Samuel ha-Lévi, date à partir de laquelle les Juifs n'avaient plus occupé de fonctions dans la maison du roi. L'obligation faite aux Juifs par le roi Henri II en 1371 de porter un signe distinctif était, dit-il,

34. Alfonso de Valladolid, Mostrador de Justicia, ed. Walter Mettmann, Opladen, Westdeutscher Verlag (Abhandlungen der Nordrhein-Westfälischen Akademie der Wissenschaften, 92/1-2), 1994-1996.

35. José María Soto Rábanos prépare actuellement une édition du traité qui devrait être publiée dans la collection Nueva Roma, Bibliotheca graeca et latina Aevi Posterioris, du CSIC, Madrid. 
une mesure qui correspondait aux canons de l'Église mais qui, jusqu'alors, n'avait jamais eu cours en Espagne, où les Juifs se mêlaient indistinctement aux « fidèles », ce qui était contraire aux lois divines. Pablo de Santa María attribue ensuite à juste titre au roi Jean Ir (1379-1390) le fait d'avoir interdit aux Juifs l'accès à tous les offices publics et de leur avoir ôté la juridiction criminelle au sein de leur communautée ${ }^{36}$.

Pablo de Santa María, par ailleurs, commenta les massacres de 1391, dus aux prédications dans l'église de Séville d' " un certain archidiacre, peu lettré et d'honnête vie - in literatura simplex et laudabilis vitae », mais y vit un bienfait: les Juifs, face à ces malheurs, dit-il, se rendirent compte en grand nombre que Dieu n'était pas avec eux. Ils commencèrent à « scruter les Écritures et, illuminés par Dieu, ils connurent leur erreur » et se convertirent. Du règne de Jean II (1406-1454) sous lequel il vivait, Pablo de Santa María retient que beaucoup de mesures furent prises contre « l'impiété judaïque » et que « l'infidélité tant juive que sarrasine a été abaissée ». Pour l'évêque de Burgos, le haut statut dont avaient joui les Juifs pendant longtemps «avec les rois et les princes de la terre, tant ecclésiastiques que laïcs » les avait empêchés de voir la lumière et de se convertir ${ }^{37}$. Dans sa Somme des chroniques d'Espagne, achevée en 1404, Pablo de Santa María ne mentionnait « les Juifs » qu'à propos de la conversion forcée par le roi Sisenand en expliquant que «tous ceux qui ne voulurent pas se convertir sortirent d'Espagne et n'y revinrent pas jusqu'au temps du roi maudit Wittiza qui leur donna l'autorisation et les fit revenir $»^{38}$.

Dans son Rimado de Palacio, Pero López de Ayala accusait «les Juifs » d'opprimer le pauvre peuple sous le poids des dettes et des impôts, mais réservait la locution «peuple des Juifs » pour ceux qui vivaient en Palestine avant la dispersion : «Le peuple des Juifs, pour qui Notre Seigneur / fit de tels miracles, par la suite en grande erreur / tomba... $»^{39}$. Au début de son Scrutinium,

36. Pablo de Santa Maria, Scrutinium Scripturarum, Burgos, apud Philippum Iuntam, 1591, dist. VI, cap. X, p. 523-524.

37. Pablo de Santa María, Scrutinium Scripturarum, dist. VI, cap. X, p. $524-525$.

38. Pablo de Santa María, Suma de las Crónicas de España, ed. José Luis Villacañas Berlanga, Biblioteca Saavedra-Fajardo, p. 13 [www.saavedrafajardo. org/Archivos/LIBROS/Libro0032.pdf].

39. Pero López de Ayala, Rimado de Palacio, v. 6051-6053. 
Pablo de Santa María avait expliqué que le Messie était venu pour sauver, non seulement le populus Israeliticus, les descendants de Jacob et tous les Israélites et aussi les aliae nationes per mundum dispersae, que ce salut n'était pas limité au seul populum ex Israel descendentem secundum carnem mais l'étendait ad caeteras nationes gentium et ad caeteras regiones terrae ${ }^{40}$. Pour ce dernier qui provenait du judaïsme, Israël était donc un «peuple» et le salut avait été annoncé à toutes les nations du monde.

Le dominicain Lope de Barrientos (1382-1469), défenseur des conversos, parle effectivement du populus iudaicus dans la Clavis sapientiae, une encyclopédie du savoir rédigée dans les années 1440, quoiqu'il mentionne aussi, sous l'entrée «Ihesus », que « les Juifs » eurent deux sauveurs imparfaits, Moïse et Cyrus ${ }^{41}$. Mais c'est dans la «question » que lui pose, sans doute vers 1449, le bachelier Alfonso González de Toledo, que le problème est plus visiblement posé. Alfonso González demandait ce qu'il fallait comprendre du décret de Gratien qui, s'appuyant sur le IV e Concile de Tolède, condamnait comme sacrilège celui qui donnait un office public aux Juifs «ou à ceux qui viennent des Juifs - Iudaei aut hi qui ex Iudaeis sunt» (D. 17, c. 4, 31); c'était cette partie qui créait un doute que n'éclaircissaient pas, disait Alfonso González, les gloses d'Huguccio ou de Johannes Teutonicus. En s'efforçant de répondre, Lope de Barrientos utilise souvent le qualificatif de «peuple» pour les Juifs : «Il semble que l'Ancienne Loi montrait Jésus Christ comme une chose [sic] imparfaite parce qu'elle était donnée à un peuple rude et imparfait en comparaison avec la perfection qui viendrait par Jésus Christ. Ce peuple était ainsi comparé au jeune serviteur qui vit avec un maître, comme le dit l'Apôtre dans son épître aux Galates »; plus avant, il se réfère aux convertis récents du «peuple judaïque » que le Seigneur choisit comme apôtres ${ }^{42}$.

40. Pablo de Santa Maria, Scrutinium Scripturarum, dist. I, cap. I, p. 105-106.

41. Antonia Rísquez Madrid, Edición crítica y comentario de Clavis sapientiae. La llave del saber de Lope de Barrientos en la Edad Media española, Madrid, Universidad Complutense, 2010 [http://eprints.ucm.es/25745/], §318, p. 709 et $\$ 174$ p. 480 .

42. Respuesta de D. Lope de Barrientos a una duda, BNE Ms 1181, fo 128v154, ed. Isabel García Díaz, Biblioteca Saavedra Fajardo [www.saavedrafajardo. org/Archivos/LIBROS/Libro0143.pdf], fo 130v: «Pareçe que la Ley Vieja disponia a Jhesu Christo ansy como cosa inperfecta porque se dava a pueblo rudo 
Dans le grand débat suscité en 1449 par l'attaque contre les Juifs et les conversos de Tolède, que justifia le Memorial du bachelier Marcos García de Mora, et qui aboutit à la « Sentence-Statut» qui expulsa tous les conversos du gouvernement de la ville, Lope de Barrientos se place du côté des défenseurs des convertis, comme le feront Fernán Díaz de Toledo el Relator, Diego de Valera, Alfonso de Cartagena, Juan de Torquemada ou encore Alfonso de Oropesa.

Les rebelles de Tolède en 1449 se plaignaient des convertis descendant du « lignage », du " pervers lignage » ou de l' « espèce » - ralea - des Juifs, ennemis de la ville et de ses habitants « vieux chrétiens », cause de la perte et de la destruction «des biens et de l'honneur de la patrie » ainsi que de la foi chrétienne ${ }^{43}$. Le bachelier Marcos García de Mora, dit Marquillos, qualifiait des convertis de «quatrième genre et état» car ils provenaient de la «lignée altérée » des Juifs. À son tour, le relator Fernán Díaz de Toledo que Marquillos appelle «Mose Hamomo », dans son Instrucción, disqualifia Marcos García en rappelant qu'il n'était "pas homme pour cela ni même en raison de son vil lignage du hameau de Mazarambros, d'où il est originaire » et lui conseilla de reprendre la charrue comme son père et son grand-père ${ }^{44}$.

Le confesseur du roi Lope de Barrientos distingue dans sa réponse à Alfonso González ceux qu'il appelle « les Juifs de nom et de fait », c'est-à-dire ceux qui sont nés dans et suivent la loi de Moïse, et les simples « Juifs » qui, pour lui, désignent tout autant les convertis que les chrétiens qui suivraient les prescriptions mosaïques, et il en conclut que «ceux qui suivent la foi des Juifs, il est juste qu'ils soient et doivent être écartés des honneurs et des offices publics, comme les Juifs eux-mêmes ». Ce qui

e inperfecto en conparaçion de la perfecçion que avia de ser por Jhesu Christo. Lo qual este pueblo era conparado al moço que bive con amo, ansy como dize el apostol en la epistola que escrivio a los Galatas » ; voir aussi $\mathrm{f}^{\circ} 149 \mathrm{r}$.

43. Eloy Benito Ruano, Los orígenes del problema converso, Madrid, Real Academia de la Historia, 2001, p. 86-90, cit. par Rica Amrán, « De Pedro Sarmiento a Martínez Silíceo: la "génesis" de los estatutos de limpieza de sangre », Autour de l'Inquisition. Études sur le Saint-Office, ed. Rica Amrán, Paris, Indigo-Université de Picardie Jules Verne, 2002, p. 33-56.

44. Eloy Benito Ruano, Los orígenes del problema converso, p. 103-104. Alfonso de Cartagena, Defensorium unitatis christianae, ed. P. Manuel Alonso, Madrid, Consejo Superior de Investigaciones Científicas, Instituto Arias Montano, app. II, p. 354. 
importe, poursuit Lope de Barrientos, n'est pas le lignage mais la foi et, citant saint Ambroise, il affirme que «le père des Juifs est le diable, mais selon la succession du péché et non selon la succession de la chair »; il donne aussi comme exemple le fait que le sacerdoce ne vient plus "par héritage ou succession lignagère comme dans la Loi Ancienne» mais par «perfection de vie et propreté - limpieza - de justice », et que le fait de tenir compte du lignage est donc un affront. À ceux qui affirmaient qu'on trouvait beaucoup de convertis qui suivaient toujours «la foi des Juifs », l'évêque répond qu' «il est possible qu'il y en ait quelques-uns, mais même s'il en était ainsi, ce serait chose injuste et inhumaine que de salir et de diffamer tout leur lignage, comme s'efforcent d'affirmer beaucoup de malveillants $»^{45}$.

Le texte de Lope de Barrientos pose effectivement le problème, non au niveau du «lignage » ou de la «succession de la chair», mais à celui de la foi. C'est bien à ce niveau que se situe désormais la controverse et que se fixe le regard des auteurs castillans. Juan de Torquemada, peu après la rébellion de Pedro Sarmiento à Tolède, rédigea un traité contre les ennemis des fideles Christi, assimilant les convertis aux vieux chrétiens. Il y mentionne la conversion du populus Israeliticus à la foi du Christ, condamne les persecutores fideles populi Israelitici, rappelle que la «sainte mère Église est entièrement édifiée à partir du genus des Juifs et des gentils, et continue son accroissement» et que tous les chrétiens proviennent de la nation des gentils ou de la generatio des Juifs, trouve scandaleux que l'on impute aux générations suivantes les «péchés» des pères ou que l'on affirme que la generatio et genus Iudaeorum fut condamnée comme mauvaise, infidèle et adultère dans la foi, évoque les promesses bibliques faites au populus Israeliticus et réfute les arguments avancés pour appuyer la réprobation populi aut generationis Iudaeorum ${ }^{46}$. Il est intéressant de constater que les traducteurs du texte emploient des mots comme « race » ou «nation » là où le latin utilise generatio, genus ou populus. Il est également intéressant de remarquer

45. Ibidem, fo $132 \mathrm{v}-133$, fo $134 \mathrm{v}-135, \mathrm{f}^{\mathrm{o}} 138 \mathrm{v}, \mathrm{f}^{\mathrm{o}} 141 \mathrm{v}-142, \mathrm{f}^{\mathrm{o}} 144 \mathrm{v}-145$. La source chez saint Ambroise est : In Luc. IV, 54.

46. Tratado contra los Madianitas e Ismaelitas, de Juan de Torquemada, ed. Carlos del Valle \& alii, Madrid, Aben Ezra ediciones, 2002, p. 126, 127, 140-141, 149, 160, 171. 
que les mots utilisés par les rédacteurs de la Sentence de 1449 à Tolède, «lignage », « espèce », sont interprétés comme « sang » et limpieza de sangre alors qu' aucun de ces termes n'apparaît dans le texte ${ }^{47}$.

Alfonso de Cartagena, évêque de Burgos et fils de Pablo de Santa María, prit également la défense des conversos dans son Defensorium unitatis christianae. Il y recourt au mot "peuple» pour désigner les Juifs, mais pas uniquement puisque la «loi de l'Écriture » les distingua des autres peuples qui n'avaient que la «loi de la nature» et n'étaient que des gentes. Il conclut sa première partie en expliquant que « tous les humains - gentes - du monde » ont reçu la grâce de la rédemption et que le baptême fait qu'Israélites et Gentils ne font plus deux peuples mais se fondent en un seul peuple nouveau ${ }^{48}$.

La définition de ces mots a visiblement changé de sens au cours des siècles, même si populus, nationes et gentes font partie $\mathrm{du}$ vocabulaire biblique, notamment dans Isaïe. Dans le Vocabulaire universel en latin et en langue vulgaire que le chroniqueur Alfonso de Palencia adresse à la reine Isabelle la Catholique en 1490, la définition de ces mots est donnée en espagnol. Gente, dit-il, est l'ensemble de ceux qui sont issus d'une même origine, d'une même famille, et il ajoute qu'il y a une différence entre ce mot et celui de «nation» «car la nation requiert le sol de la patrie et la gente est le rassemblement de beaucoup de descendants d'une même personne ». " Nation » provient, écrit-il, de «naître » et les nations se disent de ceux qui sont liés par la parenté et la langue, «comme la nation allemande et italique et française »; s'appuyant sur Sextus Pompeius Festus, il précise que la nation est «le lignage des hommes qui ne proviennent pas d'ailleurs mais qui y sont nés ». " Peuple», enfin, est pour lui un ensemble d'hommes liés par un consensus juridique et une communication voulue, définition qui reprend celle d'Isidore de Séville, à laquelle Alfonso de Palencia ajoute le fait qu'au singulier le mot signifie les habitants d'une même ville. Quant à «secte», il lui donne la

47. Rica Amrán, «De Pedro Sarmiento a Martínez Siliceo: la "génesis" de los estatutos de limpieza de sangre », op. cit., qui suit Benzion Netanyahu, Los orígenes de la Inquisición, Barcelona, 1999, p. 332-347.

48. Guillermo Verdín-Díaz, Alonso de Cartagena y el Defensorium Unitatis Christianae, Oviedo, Universidad, 1992, cap. 4, p. 115 ; théorème 3, p. 142. 
définition d'Isidore de Séville et lui ajoute celle de la « séparation par division; de là appelle-t-on sectes celles des philosophes ou des hérétiques $»^{49}$.

Lorsqu'en 1459 le franciscain Alfonso de Espina consacre le troisième livre de son Fortalitium fidei à la "guerre des Juifs contre la forteresse de la foi », il en parle tout de suite comme d'une « lignée insensée » - Iudeorum vesana progenies - et s'il se contente souvent d'accoler au mot « Juif » toutes sortes d'épithètes péjoratives, il évoque aussi le populus ou le populus iudaicus qui descend de Jacob et la generatio; de cette dernière provient la parentela, une descendance $«$ horrible et abominable $»^{50}$.

Il est évident que les auteurs castillans du $\mathrm{Xv}^{\mathrm{e}}$ siècle ne considèrent pas que les Juifs soient une nation. Ils sont une generatio ou un genus, c'est-à-dire qu'ils ont une origine commune, et ils constituent un lignage conformément à cette commune origine. Ils furent, et ils sont aussi, un peuple, c'est-à-dire un groupe humain lié par une loi et par le désir de vivre ensemble, mais qui ne possède pas de territoire en propre. Tout en faisant partie des Castillans et donc de la «nation» castillane, ils en diffèrent en cela ${ }^{51}$. Les défenseurs des conversos soutiennent que, de par leur conversion, ils doivent être pleinement intégrés à la communauté des habitants du royaume, tandis que leurs adversaires prétendent les maintenir dans un statut juridique inférieur, semblable à celui qui régissait les non-chrétiens, en arguant qu'ils ne sont effectivement pas des chrétiens mais des hérétiques. Ils leur appliquent donc toutes les prescriptions ecclésiastiques et légales qui avaient été prises au cours de l'histoire contre les Juifs et les hérétiques.

Le débat «social» est ainsi devenu un débat «religieux». Nul ne conteste le fait que les Juifs ne disposent pas des mêmes

49. Alfonso de Palencia, Universal vocabulario en latín y en romance, ed. John M. Hill, Madrid, Real Academia de la Historia, 1957, p. 84,127, 153 et 170 .

50. Alfonso de Espina, Fortalitium fidei, Lyon, 1487, lib. III. Voir Alisa Meyuhas Ginio, La forteresse de la foi. La vision du monde d'Alonso de Espina, moine espagnol ( $i$-1466), Paris, Cerf, 1998.

51. Adeline Rucquoi, "'Por la nasción de España': Castilla en el concierto europeo del siglo XV», Arquitectura tardogótica en la Corona de Castilla. Trayectorias e intercambios, ed. Begoña Alonso Ruiz \& Fernando Villaseñor Sebastián, Sevilla - Santander, Universidad de Sevilla - Universidad de Cantabria, 2014, p. 13-32. 
droits que les chrétiens. Les auteurs du $\mathrm{Xv}^{\mathrm{e}}$ siècle reviennent sur le vieux thème de l'antijudaïsme et répètent à l'envi que leur persistance dans l'erreur, leur cécité, les a fait tomber dans un état de servitude. Or l'esclave n'a pas de droits. Le facteur «temps », qui se traduit par la generatio ou la lignée, ne fait qu'aggraver les choses. Car, si le lignage est, pour un noble, une garantie de bonnes mœurs et de vertus transmises de génération en génération - «L'hidalguía est la noblesse qui vient aux hommes de leur lignée », dit la Partida, II, XXI, 3 -, l'obstination dans l'erreur ou dans le péché pèse lourdement sur les descendants : le fils d'un esclave ne peut que rester esclave. Lignage et lignée sont en effet des termes qui deviennent primordiaux dans les discours castillans $\mathrm{du} \mathrm{XV}^{\mathrm{e}}$ siècle.

Alfonso de Cartagena utilise la loi Gallus qui reconnaissait aux citoyens romains tombés en esclavage dans un autre pays, et même à leurs fils et petits-fils, la possibilité de récupérer leur citoyenneté et leurs biens s'ils s'échappaient et revenaient à Rome. Dans son Commentaire à la loi Gallus De postumis instituendis vel exheredandis, rédigé vers 1434, il compare les Juifs aux Romains qui seraient devenus esclaves, et en déduit que celui qui se convertit à la foi catholique doit être « restitué » dans son honneur et dans ses biens, donc dans ses droits, et par conséquent assimilé pleinement aux chrétiens, sans aucune distinction ${ }^{52}$. Diego de Valera, pour sa part, avait affirmé en 1441 dans le « Miroir de la vraie noblesse » que le Juif qui était noble selon sa loi ou sa communauté, non seulement devait conserver cette condition en se convertissant, mais la voyait encore améliorée car, disait-il, «dans quelle nation trouvera-t-on autant de nobles que dans celle des Juifs, là où se trouvèrent tous les prophètes et les patriarches et saints pères, tous les apôtres et finalement notre bienheureuse Dame sainte Marie et son fils béni Dieu et homme véritable, notre Rédempteur, qui choisit pour lui ce lignage comme étant le plus noble? ». Transformés en esclaves «faibles, couards et diminués », les Juifs peuvent sortir de leur captivité, et récupérer leur ancienne condition, mais Valera, au contraire d'Alfonso de Cartagena, reconnaît que le processus peut être lent car, après

52. Rafael Sánchez Domingo, El derecho común en Castilla. Comentario a la Lex Gallus de Alonso de Cartagena, Burgos, Santos, 2002. 
« mille ans de captivité », les honneurs, les dignités et les forces corporelles ne se retrouvent pas immédiatement ${ }^{53}$.

Même si Diego de Valera utilise le mot «nation » pour les Juifs, un mot qui, à l'époque, commence à désigner des communautés «nationales », dotées d'un territoire et de lois civiles spécifiques, il lui accole le vocable «lignage». C'est sous l'appellation de «peuple» que l'on trouve le plus souvent ceux qui vivaient sous la loi de Moïse, comme le disent les textes. Ce «peuple» est en fait un «lignage » qui descend de Juda ou de Jacob, donc une constance dans le temps qui persiste dans l'erreur et l'aveuglement. Le glissement sémantique que nous constatons entre le $\mathrm{XIII}^{\mathrm{e}}$ et le $\mathrm{XV}^{\mathrm{e}}$ siècle se polarise désormais sur la religion et la lignée.

Il faut replacer ce glissement sémantique dans son contexte. Les Castillans du $\mathrm{Xv}^{\mathrm{e}}$ siècle, dans un monde qui a subi de nombreuses épidémies de peste depuis celle de 1348 et qui a été bouleversé par le Grand Schisme dans l'Église, dans un pays qui a été vaincu par les Portugais et les Anglais à Aljubarrota en 1384 et qui connaît une guerre civile larvée menée par des factions de la noblesse, se posent indubitablement les mêmes questions que l'ensemble de leurs contemporains en Europe : c'est le sentiment de peur et d'insécurité si bien étudié par Jean Delumeau. Le problème du salut se décline alors sous deux aspects, celui du sang à partir du sang versé par le Christ pour la rémission des péchés, et celui du péché originel, hérité et non pas commis.

La question du sang se confond alors, en Castille, avec celle du lignage. C'est par le sang que se transmettent les vertus ou les vices des ancêtres. Mais c'est aussi le sang du Christ qui «lave» les péchés et, en particulier, le péché originel. Car, à la suite du péché d'Adam, tous les hommes ont perdu les qualités qui leur avaient été attribuées au moment de la Création, lorsqu'ils avaient été faits à l'image d'un Dieu dont la noblesse était le premier attribut. À la suite du péché originel, les hommes sont définitivement souillés, maculés, et cette macule se retrouve et se transmet par le sang. L'eau du baptême lave la souillure originelle, mais celle-ci laisse des traces et le chrétien n'est plus sûr d'aller

53. Diego de Valera, Espejo de verdadera nobleza, ed. Mario Penna, Prosistas castellanos del siglo XV, B.A.E. t. 116, Madrid, 1959, p. 102-104. Adeline Rucquoi, « Noblesse des conversos? », "Qu'un sang impur... » : les conversos et le pouvoir en Espagne à la fin du Moyen Âge, Aix-en-Provence, Université, 1997, p. 89-108. 
en paradis. C'est le purgatoire qui l'attend, état dans lequel il ne pourra plus compter que sur les prières et les offrandes de ceux qui vivent après lui ${ }^{54}$. La "propreté »-limpieza-de l'âme requiert donc d'abord le baptême, ensuite une vie vertueuse, et enfin une dernière «purgation » avant d'atteindre la demeure céleste.

Les traités de noblesse se calquent sur ce schéma et expliquent que la noblesse véritable, la noblesse ontologique ou « théologale», commence par l'obtention de la condition nobiliaire par la voie du gouvernement de la res publica, par celle des armes ou des lettres, et doit se poursuivre au moins à travers quatre générations durant lesquelles une vie vertueuse permettra de «laver» le sang souillé afin de le «purifier» de la vilenie des origines ${ }^{55}$. La plèbe est donc naturellement pécheresse depuis le péché originel et son sang est épais et sale ; le noble a, pour sa part, réussi à «laver» son sang, à échapper au péché, à s'assurer le salut grâce à son haut lignage, c'est-à-dire au nombre de générations qui l'ont précédé et ont eu le temps de «laver» leur sang de l'impureté originelle. Le seul être humain qui soit né sans la macule originelle est la Vierge Marie et les traités qui glosent l'Immaculée Conception fleurissent en Espagne au $\mathrm{XV}^{\mathrm{e}}$ siècle, tandis que les confréries animées par les dominicains affrontent sur la question du sang du Christ celles qu'inspirent les franciscains. On peut se demander quelle fut, dans l'élaboration de ces théories, l'influence des notions de pureté et d'impureté que véhiculaient les lois juive et musulmane. $\mathrm{Au} \mathrm{XIII}{ }^{\mathrm{e}}$ siècle, le poète Todros Abulafia (1247-p.1300) exaltait la jeune musulmane, "même si elle n'est ni belle ni pure ", aux dépens de la jeune chrétienne, «même si elle est radieuse comme le soleil », car, disait-il, cette dernière était impure, ne prenait pas à coeur la prostitution, et ignorait tout de l'art du sexe, alors que « toute fille arabe a le charme et la beauté (...) Elle sait tout sur la fornication et la débauche $\gg^{56}$.

54. Adeline Rucquoi, « Mancilla y limpieza: la obsesión por el pecado en Castilla a fines del siglo XV », Os «últimos fins» na cultura ibérica dos séculos XV-XVIII (Porto, 19-21 outubre 1995), Porto, Instituto de Cultura Portuguesa, 1997, p. 113-135.

55. Adeline Rucquoi, «Être noble en Espagne aux XIV $-\mathrm{XVI}^{\mathrm{e}}$ siècles », Nobilitas. Funktion und Repräsentation des Adels in Alteuropa, herausgegeben von Otto Gerhard Oexle \& Werner Paravicini, Göttingen, Vandenhoeck \& Ruprecht, 1997, p. 273-298.

56. David Nirenberg, «Love between Muslim and Jew in medieval Spain : a triangular affair », Jews, Muslims and Christians in and around the Crown of Aragon. Essays in Honour of Prefessor Elena Lourie, Leiden, Brill, 2003, 
La question religieuse est donc au cœur de la pensée castillane, qu'elle soit ouvertement exprimée ou qu'elle informe les traités politiques et de noblesse. Lorsque le relator Fernán Díaz de Toledo disqualifie son adversaire, Marquillos, en évoquant son «vil lignage » et l'absence de noblesse de sa famille de rustici, il s'inscrit dans cette large perspective culturelle.

Il n'est donc pas étonnant que les Juifs soient désormais perçus, non plus comme l'une des catégories sociales du royaume, mais comme les représentants d'une religion étrangère, et que tous les préjugés et accusations anciennes leur soient de nouveau appliqués. «Le Juif » remplace « les Juifs » et son lignage, donc son sang, ne peut être que souillé puisqu'au péché originel s'ajoute celui de l'obstination dans l'erreur. Si le Castillan se confond désormais avec le vieux chrétien, c'est-à-dire avec le descendant d'une longue lignée purifiée dans le christianisme depuis la venue du Christ, le Juif n'est plus un Castillan. Les appellations de «peuple» ou de «nation» qui lui sont appliquées en font un étranger. Les conversos eux-mêmes, qui ne peuvent se targuer d'un « haut lignage », ne peuvent pas non plus être des Castillans à part entière à la fin du $\mathrm{Xv}^{\mathrm{e}}$ siècle $^{57}$.

rucquoi@ehess.fr

p. 127-155. Peter Cole, The Dream of the Poem: Hebrew Poetry from Muslim and Christian Spain, 950-1492, Princeton University Press, 2007.

57. Sur les Juifs et «le» Juif, voir David Nirenberg, Anti-Judaism: the Western Tradition, New York, W.W. Norton, 2013, et l'analyse de cet ouvrage par Maurice Kriegel, «L'esprit tue aussi. Juifs "textuels" et Juifs "réels" dans l'histoire », Annales HSS, octobre-décembre 2014, p. 875-899. 